\title{
(6) OPEN ACCESS Accumulated workloads and the acute:chronic
workload ratio relate to injury risk in elite youth
football players
}

\author{
Laura Bowen, ${ }^{1,2}$ Aleksander Stefan Gross, ${ }^{2}$ Mo Gimpel, ${ }^{2}$ François-Xavier Li ${ }^{1}$
}

'School of Sport, Exercise and Rehabilitation Sciences, University of Birmingham, Birmingham, UK

${ }^{2}$ Southampton Football Club, Southampton, UK

Correspondence to Dr François-Xavier Li, School of Sport, Exercise and Rehabilitation Sciences, University of Birmingham, Birmingham B15 2TT, UK; f.x.li@bham.ac.uk

Accepted 19 June 2016 Published Online First 22 July 2016
CrossMark

To cite: Bowen L, Gross AS, Gimpel M, et al. Br J Sports Med 2017:51:452-459.

\section{ABSTRACT}

Aim The purpose of this study was to investigate the relationship between physical workload and injury risk in elite youth football players.

Methods The workload data and injury incidence of 32 players were monitored throughout 2 seasons. Multiple regression was used to compare cumulative $(1,2,3$ and 4-weekly) loads and acute:chronic (A:C) workload ratios (acute workload divided by chronic workload) between injured and non-injured players for specific GPS and accelerometer-derived variables:total distance (TD), high-speed distance (HSD), accelerations (ACC) and total load. Workloads were classified into discrete ranges by $z$-scores and the relative risk was determined.

Results A very high number of ACC ( $\geq 9254)$ over 3 weeks was associated with the highest significant overall (relative risk $(R R)=3.84$ ) and non-contact injury risk $(R R=5.11)$. Non-contact injury risk was significantly increased when a high acute HSD was combined with low chronic HSD (RR=2.55), but not with high chronic HSD $(R R=0.47)$. Contact injury risk was greatest when $A: C$ TD and $A C C$ ratios were very high (1.76 and 1.77, respectively) $(R R=4.98)$.

Conclusions In general, higher accumulated and acute workloads were associated with a greater injury risk. However, progressive increases in chronic workload may develop the players' physical tolerance to higher acute loads and resilience to injury risk.

\section{INTRODUCTION}

Football has evolved into a much faster, intensive and more competitive game, with physical and technical demands increasing substantially over the past few years. ${ }^{1}$ To increase the chances of success, coaches implement training loads, which challenge the boundaries of what the players can achieve without exceeding what their bodies can tolerate. ${ }^{2}$ According to Selye's General Adaptation Syndrome, ${ }^{3}$ training stimuli below the optimum are insufficient to produce adaptations. Conversely, stimuli above the optimum may lead to overtraining, which is largely associated with a higher incidence of injury. ${ }^{4}$ Hence, an appropriate balance between training, competition and recovery is required to attain peak performance and injury avoidance. ${ }^{5}$ However, this balance is not always adequately maintained, as highlighted by the higher injury rate in football than in many other team sports, ${ }^{6}$ with $\sim 50$ injuries within an elite squad of 25 players per season. $^{7}$ Thus, understanding and monitoring the training programmes of football players is vital to ensure that the optimal training load is implemented. ${ }^{2}$ Ultimately, this will potentially increase positive training adaptations and reduce the prevalence of injury in football. ${ }^{8}$

The introduction of global positioning system (GPS) into sports has led to many studies which objectively quantify training loads. However, despite growing interest, research into the relationship between these training loads and injury is still in its infancy. A higher injury risk has been found with increased acute GPS-derived workloads in Australian football and rugby league. ${ }^{2}{ }^{4}$ Research conducted over a longer period of time with larger sample sizes was required to further understand the injury-workload relationship. Consequently, Colby et $a l^{9}$ examined the relationship between accumulated GPS and accelerometer-derived loads and injury in Australian football players. During preseason and in season, 3-weekly workloads were indicative of a greater injury risk. Ultimately, studies must consider the effect of the accumulation of load to fully understand the relationship between injury and workload.

Furthermore, because of the individual physiological responses to movement demands in football ${ }^{10}$ categorising risk by absolute workloads alone may not completely explain relationships with injury across all players. Previous studies examining the relationship between workload and performance have assessed the absolute 1 week workload (acute workload) relative to 4-week chronic workload (4-week average acute workload). ${ }^{11} \mathrm{~A}$ workload index can then be calculated, indicating whether the individual's acute workload is greater than, less than or equal to the preceding chronic workload they have been prepared for. This is the acute:chronic (A:C) workload ratio. ${ }^{12}$

Using this concept in cricket, fast bowlers were three times more likely to get injured when the acute bowling workloads were double the chronic loads. ${ }^{13}$ Similarly in rugby, when the chronic total distance was high, very high spikes in acute total distance increased the injury risk. However, players with a high chronic load were more resistant to injury for moderate and moderate-high A: $\mathrm{C}$ workload ratios than those with lower chronic workloads, suggesting certain higher loads have a protective effect. ${ }^{12}$ Furthermore, Gabbett ${ }^{14}$ recently proposed that the prescription of training load may be more indicative of injury than the load itself. His training-injury prevention paradox states that excessive, rapid increases in load heighten the risk of injury, whereas chronic exposure to higher loads augments the physical capacities of the athletes 
making them more resilient to injury, while also enhancing performance. Thus, the assessment of the A:C workload ratio, for high and low chronic loads, may provide a more comprehensive prediction of injury risk than absolute workload alone. Evidence of this has been recently demonstrated in A-League football, where metres per minute in the 1 and 4 weeks prior to injury were significantly higher than the seasonal average. ${ }^{15}$ Although this was the first study to examine the relationship between GPS-derived workloads and injury in football, only 16 injuries were analysed and match data were not recorded, consequently warranting further research.

Despite the inflated injury incidence ${ }^{6}$ and physical demands of the sport, ${ }^{1}$ to date, there is very limited research exploring the contribution of GPS-derived/accelerometer-derived load monitoring to injury prediction in football. Furthermore, no studies have examined the contribution of accumulated workloads and A:C workload ratios to injury risk. Therefore, this study aimed to examine the relationships between accumulated workloads and A:C workload ratios with injury risk in elite youth football players across two seasons.

\section{METHODS}

\section{Participants}

Data were collected from elite youth football players $(n=32)$ from one English Premier League category 1 academy (age: 17.3 \pm 0.9 years, stature: $180.0 \pm 7.3 \mathrm{~cm}$, body mass: $74.1 \pm 7.0 \mathrm{~kg}$ ). The players trained on a full-time basis and played competitive fixtures within the Under 18 or Under 21 Premier League during the 2013-2014 and 2014-2015 seasons. Twenty (63\%) participants competed in both seasons and $12(38 \%)$ participants competed in one season-resulting in 52 individual football seasons. Goalkeepers were excluded from the study due to the different nature of their activity. Ethical approval was obtained from the Research Ethics Committee of The University of Birmingham.

\section{Quantifying workload}

Workload was quantified using GPS, with data collected from all on-pitch training sessions and matches. The GPS units (Viper V.2, StatSports, Ireland) were placed between the scapulae of the players in bespoke vests. These units sampled at $10 \mathrm{~Hz}$ and the accelerometers at $100 \mathrm{~Hz}$. Following each session, the data were downloaded using the specialised analysis software (Viper, V.2.1.3.0).

For sessions when GPS data were unavailable for a participant ( $n=480$ of $12117 ; 4 \%$ ) because he was not wearing a unit, he could not complete the entire session or the data were deemed unreliable due to the intermittent satellite signal; the data were estimated as follows:

Main training session data were estimated by calculating squad averages for drills completed.
Game data were estimated using individual season game averages (from a minimum of three matches) while considering individual game time.

The variables defined in table 1 were selected for use in this study due to their relevance to running loads (and potential injury). All the variables were obtained from the StatSports software (Viper).

\section{Definition of injury}

Injury information was classified by the academy doctor and senior chartered physiotherapists, collated, then updated in the club's database. A recordable injury was defined as one that caused any absence from future football participation. ${ }^{16}$ Injuries were classified as follows: minimal (1-3 days of football activity missed), mild (4-7 days of football activity missed), moderate (1-4 weeks of football activity missed) or severe (4+ weeks of football activity missed). ${ }^{16}$

Injuries were also categorised by injury type (description) and body site (injury location). The mechanism in which a participant acquired an injury was also classified as being non-contact or contact in nature.

\section{Data analyses}

Data were categorised in weekly blocks from Monday to Sunday. Every time a player participated in a training session or match, and data were analysed in two ways. First, the previous 1-weekly, 2-weekly, 3-weekly and 4-weekly loads were calculated. The loads were then classified into discrete ranges from very low through to very high using z-scores ${ }^{17}$ (table 2). The relationships between these weekly cumulative loads and subsequent injury were investigated.

Second, acute workload was calculated as 1-week load and chronic workload as the 4-week rolling average acute workload. The A:C workload ratio was calculated by dividing the acute workload by the chronic workload. ${ }^{13}$ A value of $>1$ represents an acute workload greater than the chronic workload and vice versa. Chronic workloads were also separated into high and low categories by the median score for each variable. ${ }^{12}$ From this, injury-workload relationships between $\mathrm{A}: \mathrm{C}$ ratios combined with high and low chronic workloads were analysed. As with accumulated workloads, the ratios were categorised based on z-scores (table 3).

\section{Statistical analyses}

The analysis was performed in a manner similar to the previous work of Colby et $a l^{9}$ and Hulin et al. ${ }^{12}$ Injury incidence was determined by dividing total number of injuries by the 'on-legs' exposure time and reported as rates per 1000 hours. Injury risks were calculated as the number of injuries sustained relative to the number of exposures to each workload

Table 1 Definition of GPS variables

\begin{tabular}{|c|c|}
\hline Variable & Definition \\
\hline TD & Total distance covered $(\mathrm{m})$ : this includes walking, jogging, fast running and sprinting \\
\hline HSD & Total distance covered $(\mathrm{m})$ above $20 \mathrm{~km} / \mathrm{h}$ \\
\hline $\mathrm{TL}$ & $\begin{array}{l}\text { Total of the forces on the player over the entire session based on accelerometer data alone } \\
\sqrt{ }\left(\left(a c a_{t=i+1}-a c a_{t=i}\right)_{2}+\left(a c l_{t=i+1}-a_{l} l_{t=i}\right)_{2}+\left(a c v_{t=i+1}-a c v_{t=i}\right)_{2}\right) \\
\text { where aca is acceleration along the anterior-posterior axis, acl is acceleration along the lateral axis and acv is } \\
\text { acceleration along the vertical axis, } i \text { is current time and } t \text { is time. This is then scaled by } 1000 .\end{array}$ \\
\hline ACC & A change in GPS speed data for at least half a second with maximum acceleration in the period of at least $0.5 \mathrm{~m} / \mathrm{s} / \mathrm{s}$ \\
\hline
\end{tabular}


Table 2 Workload classifications and boundaries for accumulated workloads over 1-4 weeks

\begin{tabular}{|c|c|c|c|c|c|}
\hline \multirow[b]{2}{*}{ Classification } & \multirow[b]{2}{*}{ Z-score } & \multicolumn{4}{|c|}{ No of weeks accumulated } \\
\hline & & 1 & 2 & 3 & 4 \\
\hline \multicolumn{6}{|l|}{ TD (m) } \\
\hline Low & -1.99 to -1.00 & $0-8811$ & $2741-21271$ & 9334-34 841 & $17555-49034$ \\
\hline Moderate-low & -0.99 to 0.00 & $8812-19758$ & $21272-39805$ & $34842-60061$ & $49035-80723$ \\
\hline Moderate-high & 0.00 to 0.99 & $19759-30714$ & $39806-58405$ & $60062-85549$ & $80724-112243$ \\
\hline High & 1.00 to 1.99 & $30715-39425$ & $58406-75104$ & 85 550-108919 & 112 244-143-917 \\
\hline Very high & $\geq 2.00$ & 39426 & 75105 & 108920 & 143918 \\
\hline \multicolumn{6}{|l|}{$\mathrm{HSD}(\mathrm{m})$} \\
\hline Low & -1.99 to -1.00 & $0-261$ & $0-755$ & $0-1294$ & $266-1886$ \\
\hline Moderate-low & -0.99 to 0.00 & $262-855$ & $756-1726$ & $1295-2609$ & $1887-3501$ \\
\hline Moderate-high & 0.00 to 0.99 & $856-1448$ & $1727-2697$ & $2610-3922$ & $3502-5122$ \\
\hline High & 1.00 to 1.99 & $1449-2047$ & $2698-3675$ & $3923-5254$ & $5123-6740$ \\
\hline Very high & $\geq 2.00$ & 2048 & 3676 & 5255 & 6741 \\
\hline \multicolumn{6}{|l|}{ ACC (no.) } \\
\hline Low & -1.99 to -1.00 & $0-721$ & $211-1751$ & $744-2861$ & $1417-4049$ \\
\hline Moderate-low & -0.99 to 0.00 & $722-1640$ & $1752-3329$ & $2862-4987$ & $4050-6688$ \\
\hline Moderate-high & 0.00 to 0.99 & $1641-2557$ & $3330-4860$ & $4988-7110$ & 6689-9330 \\
\hline High & 1.00 to 1.99 & $2558-3474$ & $4861-6485$ & $7111-9253$ & $9331-11982$ \\
\hline Very high & $\geq 2.00$ & 3475 & 6486 & 9254 & 11983 \\
\hline \multicolumn{6}{|l|}{$T L(A U)$} \\
\hline Low & -1.99 to -1.00 & $0-129$ & $32-319$ & $130-525$ & $256-743$ \\
\hline Moderate-low & -0.99 to 0.00 & $130-301$ & $320-608$ & $526-919$ & $744-1234$ \\
\hline Moderate-high & 0.00 to 0.99 & $302-473$ & $609-898$ & 920-1314 & $1235-1727$ \\
\hline High & 1.00 to 1.99 & $474-647$ & $899-1187$ & 1315-1709 & $1728-2222$ \\
\hline Very high & $\geq 2.00$ & 648 & 1188 & 1710 & 2223 \\
\hline
\end{tabular}

ACC, number of accelerations; HSD, high-speed distance; $m$, metres; TD, total distance; TL, total load.

classification. ${ }^{12}$ Exposure data were recorded as per the consensus statement on data collection procedures outlined by the Fédération de Football Association Medical Assessment Research Centre (F-MARC). ${ }^{16}$ A binary logistic regression model was used to compare workloads between injured and non-injured players for all GPS/accelerometer variables. Accumulated workload and A:C workload ratios were independently modelled as predictor variables.

Relative risk (RR) was calculated to determine the injury risk above and below given workloads or ratios. When an RR was greater than 1.00, an increased risk of injury was reported (ie, $\mathrm{RR}=1.50$ is indicative of a $50 \%$ increased risk) and vice versa. For an RR to be significant, 95\% CIs did not contain the null RR of 1.00. Data were analysed using IBM SPSS Statistics V.21.0 and reported as means and 95\% CI. Significance was accepted at $\mathrm{p}<0.05$.

\section{RESULTS}

\section{Injury incidence}

A total of 138 injuries (12.1/1000 hours 'on-legs' exposure time) were recorded for the duration of this study (2013-2014, 13.8/1000 hours; 2014-2015, 10.1/1000 hours), including contact and non-contact injuries (table 4). The ankle/foot (4.7/ 1000 hours) was the most common site of contact and noncontact injury over the two seasons, with the most common types of contact injury being haematoma/contusion (3.8/ 1000 hours) and non-contact injury being ligament sprains (2.1/ 1000 hours). Overall, the incidence of injury in competition was over four times that of training (33.5/1000 hours and 7.9/ 1000 hours, respectively). In particular, the incidence of contact injuries was considerably greater in competition than in training
(24.2/1000 hours vs 2.3/1000 hours) and despite a lower exposure to competition, $44 \%$ of contact injuries occurred in matches. The total number of days that players were absent was 3110 (22.1 \pm 52.8 days per injury).

\section{Absolute accumulated workloads \\ Total distance}

Performing a high total distance (TD; 112 244-143 918 m) over 4 weeks was associated with the greatest significant overall injury risk compared to all other distances $(\mathrm{RR}=1.64,95 \% \mathrm{CI}$ 1.05 to $2.58, \mathrm{p}=0.031$ ). TD above $143918 \mathrm{~m}$ demonstrated a risk but was statistically non-significant $(\mathrm{RR}=1.29$, 95\% CI 0.34 to $4.99, \mathrm{p}=0.710)$. Conversely, a low $(0-8812 \mathrm{~m})$ 1 -weekly TD reduced the risk of overall $(\mathrm{RR}=0.25,95 \% \mathrm{CI}$ 0.11 to $0.82, p=0.018)$ and non-contact injury $(R R=0.30,95 \%$ CI 0.11 to $0.57, \mathrm{p}=0.001$ ).

\section{High-speed running}

Moderate-high 4-weekly high-speed distance (HSD; 3502$5123 \mathrm{~m}$ ) demonstrated the greatest significant increase in noncontact injury risk when compared to other workloads $(\mathrm{RR}=2.14,95 \% \mathrm{CI} 1.31$ to $3.50, \mathrm{p}=0.003)$ and moderate-high 1-weekly HSD (856-1449 $\mathrm{m})$ showed the highest significant overall injury risk $(R R=1.73,95 \%$ CI 1.06 to $2.84, p=0.029)$. Overall and non-contact injury risks were significantly reduced at low 1-weekly HSD $(0-756 \mathrm{~m})(\mathrm{RR}=0.30,95 \%$ CI 0.13 to $0.68, \mathrm{p}=0.004 ; \mathrm{RR}=0.26,95 \%$ CI 0.08 to $0.83, \mathrm{p}=0.023$, respectively). 
Table 3 Workload classifications and boundaries for: (A) A:C workload ratios overall, (B) A:C workload ratios combined with low chronic workloads and (C) A:C workload ratios combined with high chronic workloads

\begin{tabular}{|c|c|c|c|c|}
\hline Classification & Z-score & (A) & (B) & (C) \\
\hline TD (m) & & & $(<22335 \mathrm{~m})$ & $(>22335 \mathrm{~m})$ \\
\hline Low & -1.99 to -1.00 & $0.04-0.43$ & $0.00-0.31$ & $0.28-0.59$ \\
\hline Moderate-low & -0.99 to 0.00 & $0.44-0.87$ & $0.32-0.83$ & $0.60-0.91$ \\
\hline Moderate-high & 0.00 to 0.99 & $0.88-1.31$ & $0.84-1.35$ & $0.92-1.24$ \\
\hline High & 1.00 to 1.99 & $1.32-1.75$ & $1.36-1.70$ & $1.25-1.57$ \\
\hline Very high & $\geq 2.00$ & 1.76 & 1.71 & 1.58 \\
\hline HSD (m) & & & $(<938 \mathrm{~m})$ & (>938 m) \\
\hline Low & -1.99 to -1.00 & $0.00-0.35$ & $0.00-0.26$ & $0.11-0.46$ \\
\hline Moderate-low & -0.99 to 0.00 & $0.36-0.86$ & $0.27-0.83$ & $0.47-0.90$ \\
\hline Moderate-high & 0.00 to 0.99 & $0.87-1.38$ & $0.84-1.40$ & $0.91-1.33$ \\
\hline High & 1.00 to 1.99 & $1.39-1.88$ & $1.41-1.96$ & $1.34-1.77$ \\
\hline Very high & $\geq 2.00$ & 1.89 & 1.97 & 1.78 \\
\hline ACC (no) & & & $(<1856)$ & $(>1856)$ \\
\hline Low & -1.99 to -1.00 & $0.05-0.44$ & $0.00-0.32$ & $0.26-0.57$ \\
\hline Moderate-low & -0.99 to 0.00 & $0.45-0.87$ & $0.33-0.84$ & $0.58-0.91$ \\
\hline Moderate-high & 0.00 to 0.99 & $0.88-1.31$ & $0.85-1.36$ & $0.92-1.24$ \\
\hline High & 1.00 to 1.99 & $1.32-1.76$ & $1.37-1.89$ & $1.25-1.59$ \\
\hline Very high & $\geq 2.00$ & 1.77 & 1.90 & 1.60 \\
\hline $\mathrm{TL}(\mathrm{AU})$ & & & $(<344 \mathrm{AU})$ & $(>344 \mathrm{AU})$ \\
\hline Low & -1.99 to -1.00 & $0.03-0.43$ & $0.00-0.31$ & $0.26-0.59$ \\
\hline Moderate-low & -0.99 to 0.00 & $0.44-0.87$ & $0.32-0.83$ & $0.60-0.92$ \\
\hline Moderate-high & 0.00 to 0.99 & $0.88-1.31$ & $0.84-1.35$ & $0.93-1.25$ \\
\hline High & 1.00 to 1.99 & $1.32-1.75$ & $1.36-1.86$ & $1.26-1.57$ \\
\hline Very high & $\geq 2.00$ & 1.76 & 1.87 & 1.58 \\
\hline
\end{tabular}

\section{Accelerations}

When many accelerations (ACC; $\geq 9254$ ) were performed in 3 weeks, there was a significant increase in the risk of overall $(\mathrm{RR}=3.84,95 \% \mathrm{CI} 1.57$ to $9.41, \mathrm{p}=0.003)$ and non-contact injuries $(\mathrm{RR}=5.11,95 \% \mathrm{CI} 1.75$ to $14.96, \mathrm{p}=0.003)$. Conversely, a low amount of ACC over 3 weeks (744-2861) significantly reduced non-contact $(\mathrm{RR}=0.21,95 \%$ CI 0.05 to $0.87, \mathrm{p}=0.031)$ and overall $(\mathrm{RR}=0.31,95 \% \mathrm{CI} 0.13$ to 0.76 , $\mathrm{p}=0.010$ ) injury risk.

\section{Total load}

High 1-weekly total load (TL; 474-648 AU) recorded the greatest significant relative risk for overall $(\mathrm{RR}=1.65$, 95\% CI 1.04 to $2.62, \mathrm{p}=0.032)$ and non-contact injuries $(\mathrm{RR}=2.20,95 \% \mathrm{CI}$ 1.25 to $3.9, \mathrm{p}=0.007)$. Furthermore, a very high 1 -weekly TL $(\geq 648 \mathrm{AU})$ significantly increased the incidence of a contact injury $(\mathrm{RR}=4.84,95 \% \mathrm{CI} 1.26$ to $18.55, \mathrm{p}=0.022)$. On the other hand, a low 1-weekly TL (0-130 AU) significantly reduced overall $(\mathrm{RR}=0.27,95 \% \mathrm{CI} 0.12$ to $0.60, \mathrm{p}=0.002)$, and non-contact injury risk $(\mathrm{RR}=0.31,95 \% \mathrm{CI} 0.11$ to 0.86 , $\mathrm{p}=0.024)$.

Table 5 summarises the risk of contact, non-contact and overall injury for all accumulated workloads.

\section{A:C workload ratios}

Total distance

The risk of contact injury was significantly increased when the A:C TD ratio was $\geq 1.76$ (very high) $(\mathrm{RR}=4.98,95 \% \mathrm{CI} 1.31$ to 19.02, $\mathrm{p}=0.019)$. For low chronic TD only $(<22335 \mathrm{~m})$, overall injury risk was reduced when the ratio between acute and chronic TD was low $(0-0.32)(\mathrm{RR}=0.28,95 \% \mathrm{CI} 0.09$ to $0.91, \mathrm{p}=0.030)$.

\section{High-speed running}

For low chronic HSD only $(<938 \mathrm{~m})$, non-contact injury risk was heightened when the ratio between the acute and chronic HSD was high $1.41-1.96(\mathrm{RR}=2.55,95 \%$ CI 1.15 to 5.68, $\mathrm{p}=0.022$ ). In addition, for high chronic HSD (>938 m), noncontact injury risk was also increased when the ratio was moderate-high $\quad(0.91-1.34) \quad(\mathrm{RR}=2.09,95 \% \quad \mathrm{CI} 1.06$ to 4.12 , $\mathrm{p}=0.033)$. However, a low ratio $(0-0.36)$ for all chronic HSD significantly reduced the overall injury risk $(\mathrm{RR}=0.47,95 \% \mathrm{CI}$ 0.25 to $0.9, \mathrm{p}=0.022$ ).

\section{Accelerations}

The risk of contact injuries was significantly increased when the A:C ACC ratio was over 1.77 (very high) ( $R=4.98,95 \% \mathrm{CI}$ 1.30 to $18.99, \mathrm{p}=0.019)$. Overall injury risk was reduced when the ratio between acute and chronic ACC was low (0-0.33) for low chronic accelerations only $(<1856)(\mathrm{RR}=0.29$, 95\% CI 0.09 to $0.91, \mathrm{p}=0.034$ ).

\section{Total load}

The risk of non-contact injury was significantly increased when the ratio between acute and chronic TL was moderate-high (0.88-1.32) $(\mathrm{RR}=1.87,95 \%$ CI 1.12 to $3.12, \mathrm{p}=0.016)$. Similarly, the risk of contact injury was increased when the ratio was moderate-low (0.44-0.88) $(\mathrm{RR}=1.92,95 \%$ CI 1.07 to $3.45, \mathrm{p}=0.028$ ). 
Table 4 Classification of injuries per 1000 hours

\begin{tabular}{|c|c|c|c|c|c|c|}
\hline \multirow[b]{2}{*}{ (Per 1000 hours) } & \multicolumn{2}{|l|}{ 2013-2014 } & \multicolumn{2}{|l|}{ 2014-2015 } & \multicolumn{2}{|l|}{ Total } \\
\hline & Non-contact (8.2) & Contact (5.6) & Non-contact (5.4) & Contact (4.7) & Non-contact (6.9) & Contact (5.2) \\
\hline \multicolumn{7}{|l|}{ Site } \\
\hline Ankle/foot & 2.8 & 3.3 & 1.3 & 1.9 & 2.1 & 2.6 \\
\hline Knee & 1.3 & 0.7 & 0.9 & 0.6 & 1.1 & 0.6 \\
\hline Hip/groin & 1.8 & 0.5 & 0.7 & 0.0 & 1.3 & 0.3 \\
\hline Quadriceps & 0.2 & 1.1 & 0.4 & 0.2 & 0.3 & 0.7 \\
\hline Hamstring & 0.2 & 0.0 & 1.5 & 0.2 & 0.8 & 0.1 \\
\hline Forearm/wrist/hand & 0.3 & 0.5 & 0.4 & 0.2 & 0.3 & 0.3 \\
\hline Head/neck & 0.0 & 0.5 & 0.0 & 0.6 & 0.0 & 0.5 \\
\hline Abdomen/lower back & 0.0 & 0.0 & 0.9 & 0.0 & 0.4 & 0.0 \\
\hline Lower leg & 0.2 & 0.2 & 0.2 & 0.4 & 0.2 & 0.2 \\
\hline Shoulder/arm/elbow & 0.0 & 0.2 & 0.0 & 0.0 & 0.0 & 0.1 \\
\hline Sternum/ribs/upper back & 0.0 & 0.2 & 0.0 & 0.0 & 0.0 & 0.1 \\
\hline \multicolumn{7}{|l|}{ Injury type } \\
\hline Haematoma/contusion & 0.0 & 5.1 & 0.4 & 2.4 & 0.2 & 3.8 \\
\hline Ligament sprain & 2.6 & 1.1 & 1.5 & 0.9 & 2.1 & 1.0 \\
\hline Muscle strain & 1.8 & 0.0 & 2.1 & 0.0 & 1.9 & 0.0 \\
\hline Fracture & 0.3 & 0.2 & 0.6 & 0.6 & 0.4 & 0.3 \\
\hline Other & 0.7 & 0.0 & 0.7 & 0.0 & 0.7 & 0.0 \\
\hline Tendinosis & 0.7 & 0.0 & 0.6 & 0.0 & 0.6 & 0.0 \\
\hline Joint injury & 0.7 & 0.2 & 0.2 & 0.0 & 0.4 & 0.1 \\
\hline Concussion & 0.0 & 0.2 & 0.2 & 0.2 & 0.0 & 0.2 \\
\hline Laceration & 0.0 & 0.3 & 0.0 & 0.0 & 0.0 & 0.2 \\
\hline \multicolumn{7}{|l|}{ Severity } \\
\hline Minimal & 1.5 & 2.5 & 1.1 & 0.6 & 1.3 & 1.6 \\
\hline Mild & 1.8 & 1.5 & 0.9 & 1.5 & 1.4 & 1.5 \\
\hline Moderate & 2.5 & 2.3 & 1.5 & 1.5 & 2.0 & 1.9 \\
\hline Severe & 1.3 & 0.5 & 1.5 & 1.5 & 1.4 & 1.0 \\
\hline \multicolumn{7}{|l|}{ Activity performed } \\
\hline Game & 7.9 & 22.6 & 12.5 & 24.2 & 9.9 & 24.2 \\
\hline Training & 6.3 & 3.7 & 4.8 & 2.3 & 5.6 & 2.3 \\
\hline
\end{tabular}

Table 6 summarises the risk of contact, non-contact and overall injury for all A:C workload ratios.

\section{DISCUSSION}

This is the first study to examine the relationship of accumulated GPS-derived/accelerometer-derived loads and A:C workload ratios with contact and non-contact injury incidence in football. In line with other studies examining load and injury in sport, $^{2} 491518$ many GPS/accelerometer variables were found to be significantly related to injury risk. Three-weekly accelerations $>9254$ were the strongest indicator of overall $(R R=3.84)$ and non-contact $(\mathrm{RR}=5.11)$ injury risk in this study. These findings provide empirical support for monitoring the accumulated training loads over 3 weeks, and correspond with those of Colby et $a l^{9}$ who found various 3-weekly workloads to have the strongest association with injury risk in Australian football during preseason and in season.

High 4-weekly TD (112 244-143-917 m) and 1-weekly TL (474-647 AU) also significantly increased the risk of overall and non-contact injuries ( $R R=1.64$ and 1.65 , respectively) similar to previous literature, where higher training loads resulted in a greater injury incidence. ${ }^{2}{ }^{4}$ Conversely, for HSD, a moderatehigh load over 1 (856-1448 m) and 4 (3502-5122 m) weeks resulted in higher overall $(\mathrm{RR}=1.73)$ and non-contact $(R R=2.14)$ injury incidence, respectively, compared to lower and higher HSD. Workload classification by z-scores in this study means that the greatest risk of non-contact injury was associated with the most commonly performed high-speed running distances. Non-contact injury risk was also significantly augmented for a moderate-high $\mathrm{A}: \mathrm{C}$ TL ratio $(\mathrm{A}: \mathrm{C}=0.88-1.31, \mathrm{RR}=1.87$ ) and a moderate-high A:C HSD ratio combined with high chronic HSD only (>938 m) (A:C=0.91-1.33, $\mathrm{RR}=2.09)$. Thus, when the acute and chronic stimuli are similar, the incidence of injury is increased. In addition, a high A:C workload ratio combined with low chronic HSD (<938 m) showed a significantly increased risk of non-contact injury incidence (A:C=1.41-1.96, $\mathrm{RR}=2.55)$, which was not evident when combined with high chronic HSD (A:C=1.34-1.77, $\mathrm{RR}=0.47)$. This may be indicative of underpreparedness, similar to that reported by Hulin et al, ${ }^{12}$ where the previous 4 -week chronic HSD exposure was insufficient to prepare the player for high acute bouts. The combination of these findings would suggest that optimal HSD and TL exposure should be periodised to fluctuate across a 4-week period, with the achievement of high and low workloads. In addition, the chronic exposure of HSD should be high enough to prepare the players for the necessary spikes in the A:C workload ratio. Ultimately, a certain level of training must be achieved to develop the physical capacities needed to withstand the demands of the sport. ${ }^{14}$ Players who can safely train harder may develop a greater resilience and tolerance for the progressively increasing intensity and fatigue of competition. ${ }^{1}$ 
Table 5 Injury risks associated with accumulated workloads over 1-4 weeks

\begin{tabular}{|c|c|c|c|c|c|c|c|c|c|c|c|c|}
\hline \multirow[b]{3}{*}{ Number of weeks accumulated } & \multicolumn{12}{|c|}{ Relative risk } \\
\hline & \multicolumn{3}{|l|}{1} & \multicolumn{3}{|l|}{2} & \multicolumn{3}{|l|}{3} & \multicolumn{3}{|l|}{4} \\
\hline & NC & C & Overall & NC & C & Overall & NC & C & Overall & NC & C & Overall \\
\hline \multicolumn{13}{|l|}{ TD (m) } \\
\hline Low & $0.30^{*}$ & 0.83 & $0.25^{* *}$ & 0.61 & 0.76 & 0.62 & 0.67 & 0.84 & 0.53 & 1.01 & 1.04 & 0.89 \\
\hline Moderate-low & 1.45 & 0.68 & 1.38 & 0.95 & 0.65 & 0.76 & 0.87 & 0.87 & 1.23 & 0.77 & 0.92 & 0.73 \\
\hline Moderate-high & 0.83 & 0.98 & 0.95 & 1.19 & 1.62 & $1.55^{*}$ & 1.08 & 0.84 & 1.36 & 1.06 & 0.88 & 1.19 \\
\hline High & 1.64 & 1.79 & 1.57 & 1.37 & 1.00 & 1.27 & 1.65 & 1.35 & 1.31 & 1.55 & 1.49 & $1.64^{*}$ \\
\hline Very high & 3.04 & - & 2.59 & 3.35 & - & 2.88 & 2.79 & - & 2.37 & 2.30 & - & 1.29 \\
\hline \multicolumn{13}{|l|}{$\mathrm{HSD}(\mathrm{m})$} \\
\hline Low & 0.54 & 0.79 & $0.38^{*}$ & $0.26^{*}$ & 0.91 & $0.30^{*}$ & 0.68 & 0.83 & 0.67 & 0.94 & 1.14 & 0.79 \\
\hline Moderate-low & 1.10 & 0.41 & 1.16 & 0.95 & 0.67 & 0.81 & 0.79 & 0.78 & 0.84 & 0.61 & 0.97 & 0.73 \\
\hline Moderate-high & $1.73^{*}$ & 1.74 & $1.73^{*}$ & 1.42 & 1.70 & $1.72^{*}$ & 1.40 & 1.24 & 1.15 & $2.14^{*}$ & 0.68 & $1.56^{*}$ \\
\hline High & 0.65 & 1.08 & 0.59 & 1.75 & 0.86 & 1.45 & 1.42 & 1.13 & $1.66^{*}$ & 0.68 & 1.74 & 1.26 \\
\hline Very high & 0.00 & 1.97 & 0.82 & 0.00 & - & 0.00 & 0.00 & 1.62 & 0.33 & 0.59 & - & 0.33 \\
\hline \multicolumn{13}{|l|}{ ACC (no) } \\
\hline Low & 0.47 & 0.72 & $0.35^{*}$ & 0.60 & 0.75 & 0.51 & 0.69 & 0.84 & 0.63 & 0.95 & 1.02 & 0.93 \\
\hline Moderate-low & 0.77 & 0.65 & 1.01 & 0.96 & 0.67 & 0.92 & 0.68 & 1.24 & 0.77 & 0.72 & 0.91 & 0.82 \\
\hline Moderate-high & 1.03 & 1.39 & 1.00 & 1.27 & 1.51 & 1.21 & 1.29 & 0.76 & 1.32 & 1.02 & 0.92 & 1.01 \\
\hline High & $2.25^{*}$ & 1.27 & $1.83^{*}$ & 1.10 & 1.06 & 1.37 & 1.47 & 1.49 & 1.38 & 1.64 & 1.35 & $1.66^{*}$ \\
\hline Very high & 1.31 & - & $3.06^{*}$ & $4.25^{*}$ & - & $3.19^{*}$ & $5.11^{*}$ & 1.02 & $3.84^{*}$ & $4.25^{*}$ & - & 2.37 \\
\hline \multicolumn{13}{|l|}{$\mathrm{TL}(\mathrm{AU})$} \\
\hline Low & $0.31 *$ & 0.77 & $0.27^{*}$ & 0.59 & 0.81 & 0.50 & 0.55 & 0.87 & 0.55 & 0.80 & 1.06 & 0.75 \\
\hline Moderate-low & 1.40 & 0.63 & 1.45 & 1.17 & 0.70 & 1.07 & 0.85 & 1.34 & 0.98 & 1.04 & 0.98 & 1.01 \\
\hline Moderate-high & 0.79 & 1.12 & 0.98 & 1.13 & 1.76 & 1.38 & 1.37 & 0.77 & 1.39 & 0.94 & 0.89 & 1.12 \\
\hline High & $2.20^{*}$ & 1.42 & $1.65^{*}$ & 1.45 & 0.33 & 1.03 & 1.41 & 0.95 & 1.09 & 1.64 & 1.43 & 1.20 \\
\hline Very high & 0.00 & $4.84^{*}$ & 2.00 & 0.00 & 3.04 & 1.93 & 1.39 & 2.68 & 1.59 & 1.07 & - & 1.84 \\
\hline
\end{tabular}

${ }^{*} p<0.05,{ }^{* *} p<0.001$.

ACC, number of accelerations; $C$, contact; HSD, high-speed distance; m, metres; NC, non-contact; TD, total distance; TL, total load.

The majority of studies that assess training loads and injury risk focus solely on non-contact, soft tissue injury, as these are considered largely preventable, whereas contact injuries are considered mostly unavoidable. ${ }^{8}$ However, Gabbett et al ${ }^{18}$ found higher workloads to be strongly correlated with contact injuries in professional rugby. Consistent with their findings, the present study demonstrated that very high 1 -weekly TL $(\geq 648 \mathrm{AU})$ and very high A:C ratios for TD and ACC $(\geq 1.76$ and $\geq 1.77$, respectively) were significantly related to a higher risk of contact injury (TL: $\mathrm{RR}=4.84$, TD and ACC: $\mathrm{RR}=4.98$ ). Banister et $a l^{11}$ reported acute workload as an estimate of an athlete's 'fatigue' and chronic workload as 'fitness'. In the context of this study, a larger discrepancy between acute workload ('fatigue') and chronic workload ('fitness') resulted in a greater contact injury risk than when the ratio was moderate or low (the measure of 'fitness' was similar to or higher than that of 'fatigue'). Furthermore, the ratios above which a significant risk of contact injury was recorded were higher than those for non-contact injury in this study, and previous work within Australian football, cricket and rugby league $(>1.5) .{ }^{14}$ This suggests that a higher level of fatigue (acute workload) relates to contact injury than non-contact injury. Ultimately, by increasing fitness levels and limiting fatigue, players may be able to respond more quickly to avoid the rapid, unpredictable movements preceding contact injury. ${ }^{19}$ The only exception to this was a significant risk of contact injury for a moderate-low A:C ratio of TL (0.44$0.87)$. Gabbett ${ }^{14}$ found a 'sweet spot' for the A: $\mathrm{C}$ ratio between 0.8 and 1.3 to maximise fitness and performance while reducing injury risk. Therefore, underpreparedness, or low tolerance to load, may also be a factor in the occurrence of contact injury. These findings demonstrate the multifactorial nature of injury and highlight the need for future research, specifically into contact injuries.

Total injury incidence (12.1/1000 hours) and also training (7.9/1000 hours) and match (33.5/1000 hours) incidences were similar to those recorded in the UEFA injury study involving 23 top European clubs over seven seasons. ${ }^{7}$ However, in this study, the large prevalence of contact injuries in competition goes further to highlight the importance of monitoring the A:C workload ratios, particularly during fixture congested periods, when ensuring adequate recovery between games, while maintaining optimum training loads is a challenge.

Although low accumulated workloads and A:C workload ratios demonstrated a significantly reduced injury risk across all metrics, the authors do not recommend regular training at these workloads. Football players cover $\sim 10000 \mathrm{~m}$ during a match; therefore, low $(\leq 8812 \mathrm{~m})$ weekly distances may result in the players being underprepared for the physical demands of the game, and ultimately may increase their risk of injury. Although there is no doubt that higher training loads are related to a heightened injury risk, when correctly prescribed, higher loads can also produce positive adaptations that build tolerance and resilience to fatigue and injury. $^{14}$

This was the first study to monitor injury risk using GPS from training and competition in football, providing comprehensive 
Table 6 Injury risks associated with (A) A:C workload ratios overall, (B) A:C workload ratios combined with low chronic workloads and (C) A:C workload ratios combined with high chronic workloads

\begin{tabular}{|c|c|c|c|c|c|c|c|c|c|}
\hline \multirow[b]{3}{*}{ No. of weeks accumulated } & \multicolumn{9}{|c|}{ Relative risk } \\
\hline & \multicolumn{3}{|l|}{$A$} & \multicolumn{3}{|l|}{ B } & \multicolumn{3}{|l|}{ C } \\
\hline & NC & C & Overall & NC & $\mathrm{C}$ & Overall & NC & $\mathrm{C}$ & Overall \\
\hline \multicolumn{10}{|l|}{ TD (m) } \\
\hline Low & 1.50 & 0.37 & 1.00 & 0.29 & 0.26 & $0.28^{*}$ & 1.19 & 0.62 & 0.91 \\
\hline Moderate-low & 0.96 & 1.72 & 1.25 & 1.12 & 2.12 & 1.43 & 0.62 & 1.47 & 0.98 \\
\hline Moderate-high & 1.45 & 0.44 & 0.97 & 1.43 & 0.44 & 0.97 & 1.53 & 0.91 & 1.19 \\
\hline High & 1.05 & 1.22 & 1.13 & 1.28 & 2.80 & 1.76 & 1.51 & 0.91 & 1.21 \\
\hline Very high & 0.00 & $4.98^{*}$ & 2.09 & - & - & - & - & 3.79 & 1.80 \\
\hline \multicolumn{10}{|l|}{$\mathrm{HSD}(\mathrm{m})$} \\
\hline Low & 0.60 & 0.32 & $0.47^{*}$ & 0.63 & 0.24 & 0.47 & 1.20 & 1.91 & 1.52 \\
\hline Moderate-low & 0.88 & 1.45 & 1.10 & 0.88 & 0.82 & 0.86 & 0.81 & 1.52 & 1.11 \\
\hline Moderate-high & 1.33 & 1.32 & 1.32 & 0.85 & 2.55 & 1.30 & $2.09 *$ & 0.69 & 1.27 \\
\hline High & 1.39 & 0.49 & 0.98 & $2.55^{*}$ & 0.85 & 1.82 & 0.47 & 0.54 & 0.50 \\
\hline Very high & - & 2.28 & 0.95 & - & - & - & - & 3.62 & 1.63 \\
\hline \multicolumn{10}{|l|}{ ACC (no.) } \\
\hline Low & 1.22 & 0.39 & 0.85 & 0.31 & 0.25 & $0.29 *$ & 1.37 & - & 0.71 \\
\hline Moderate-low & 0.81 & 1.75 & 1.16 & 1.32 & 1.79 & 1.49 & 0.63 & 1.66 & 1.04 \\
\hline Moderate-high & 1.52 & 0.79 & 1.15 & 1.23 & 0.59 & 0.94 & 1.49 & 1.03 & 1.25 \\
\hline High & 1.41 & 1.47 & 1.44 & 1.30 & 2.48 & 1.70 & 1.54 & 0.64 & 1.10 \\
\hline Very high & - & $4.98^{*}$ & 2.09 & - & - & - & - & 5.91 & 2.71 \\
\hline \multicolumn{10}{|l|}{$\mathrm{TL}(\mathrm{AU})$} \\
\hline Low & 1.20 & 0.38 & 0.84 & 0.50 & 0.21 & 0.37 & 0.98 & 0.60 & 0.81 \\
\hline Moderate-low & 0.84 & $1.92^{*}$ & 1.15 & 0.84 & 1.64 & 1.15 & 0.79 & 1.97 & 1.22 \\
\hline Moderate-high & $1.87^{*}$ & 0.87 & 1.34 & 1.55 & 0.77 & 1.16 & 1.93 & 0.86 & 1.34 \\
\hline High & 0.87 & 1.20 & 1.01 & 1.16 & 2.28 & 1.59 & 0.53 & 0.32 & 0.43 \\
\hline Very high & - & 2.74 & 1.17 & - & - & - & - & 6.12 & 2.67 \\
\hline
\end{tabular}

external workload analysis. The inclusion of match data accounted for match-to-match variability that has been a limitation of previous studies using estimated data. ${ }^{15}$ However, the players participated in a variety of other conditioning workloads as well as the on-field sessions that could not be quantified by GPS/accelerometer loads. ${ }^{9}$ Ultimately, the incorporation of Session rating of perceived exertion (RPE) values, as a measure of internal workload, may provide a more complete insight into the likelihood of injury, as well as taking into consideration the athlete's response to a given workload. ${ }^{13}$

The greater sampling frequency $(10 \mathrm{~Hz})$ and integrated accelerometers of the GPS units used in this study allowed for valid and reliable assessment of high intensity activity and injury risk $^{20}$ that was not possible in previous studies using lower sampling devices (1 and $5 \mathrm{~Hz}) .{ }^{12}$ However, measurement error has been found to increase with speed, regardless of sampling rate and therefore caution must still be taken when interpreting the data. $^{21}$

While GPS outcomes may be considered modifiable injury risk factors, non-modifiable factors such as age and injury history were not taken into account, despite being associated with future injury incidence. ${ }^{22}$ Furthermore, the sample size did not permit the analysis of position-specific workloads and injury risk.

Another limitation of the sample size is that the number of injury cases recorded was enough to detect moderate to strong associations between training load and injury, but too small to detect small to moderate associations. ${ }^{23}$ Future research combining data from multiple clubs would solve this issue; however, due to the competitive nature of elite sport, it may prove difficult.

In conclusion, accumulated GPS/accelerometer loads and A: $\mathrm{C}$ workload ratios were significantly related to non-contact and contact injury risk in elite youth football players. In general, the higher workloads were associated with the greater injury risks, corresponding to previous literature. Three-weekly ACC $\geq 9254$ was the strongest predictor of overall and non-contact injury risk and should therefore be monitored in practice for injury prevention purposes. In addition, the results suggest that low chronic HSD underprepare the players for the risk of high acute workloads, compared to high chronic HSD. As shown in previous research, ${ }^{14}$ it may not necessarily be higher workloads that augment injury risk but the prescription of these higher loads. Spikes in non-contact injury risk, when the acute and chronic workloads were similar, highlight the need for systematic variation in the training programme. Ultimately, high, excessive, accumulated and acute loads were related to a greater injury risk. However, progressive chronic exposure to higher workloads, including appropriate fluctuations to allow for adaptation and recovery, ${ }^{3}$ may protect the players from injury by developing their physical capacities. The findings of this study provide initial guidelines for optimal workloads in elite youth football to reduce injury occurrence. However, caution should be applied when generalising these data to different teams and sports due to the specific nature of the physical demands. 


\section{What are the findings?}

- This is the first study to examine the relationships of accumulated global positioning system-derived/ accelerometer-derived loads and acute:chronic $(\mathrm{A}: \mathrm{C})$ work load ratios with contact and non-contact injury incidence in football.

- The injury risk was greatest when a very high number of accelerations were accumulated over 3 weeks.

- Optimal high-speed running exposure should be periodised to fluctuate across a 4-week period, with the achievement of high and low distances, while ensuring that the chronic exposure is high enough to prepare the players for the necessary spikes in the $\mathrm{A}: \mathrm{C}$ workload ratio.

- Contact injuries are significantly related to 1-weekly 'spikes' in various workload measures.

\section{How might it impact on clinical practice in the future?}

- The findings of this study provide initial guidelines for implementing optimal accumulated workloads and $\mathrm{A}: \mathrm{C}$ workload ratios in elite youth football to reduce injury occurrence.

- Global positioning system-derived/accelerometer-derived variables can be modelled to predict non-contact and contact injury risk.

- $\mathrm{A}: \mathrm{C}$ workload ratios should be incorporated into clinical practice and compared to low and high chronic workloads.

Contributors All authors listed met the conditions required for full authorship. LB and F-XL designed the initial study proposal, which was presented to ASG and MG. From there, all four authors met regularly to ensure a scientifically sound study design was created. LB collated and analysed the data with the help of ASG and MG throughout the process. F-XL advised and checked the statistical analysis. LB wrote the main body of the article that was revised multiple times by all authors before being approved for publication.

Competing interests None declared.

Patient consent Obtained.

Ethics approval University of Birmingham Ethical Review Committee.

Provenance and peer review Not commissioned; externally peer reviewed.

Data sharing statement All data are within the article. However, any in-depth injury descriptions or raw data are the property of the club and as such are available to the experimenters, the players and the club only.

Open Access This is an Open Access article distributed in accordance with the Creative Commons Attribution Non Commercial (CC BY-NC 4.0) license, which permits others to distribute, remix, adapt, build upon this work non-commercially, and license their derivative works on different terms, provided the original work is properly cited and the use is non-commercial. See: http://creativecommons.org/ licenses/by-nc/4.0/

\section{REFERENCES}

1 Barnes C, Archer DT, Hogg B, et al. The evolution of physical and technical performance parameters in the English Premier League. Int I Sports Med 2014;35:1095-100.

2 Piggott $B$, Newton $M$, McGuigan $M$. The relationship between training load and injury and illness over a pre-season at an AFL club. J Aust Strength Cond 2009;17:4-17.

3 Seyle $\mathrm{H}$. The general adaptation syndrome and the diseases of adaptation. J Clin Endocrinol Metab 1946:6:117-230.

4 Gabbett TJ, Ullah S. Relationship between running loads and soft tissue injury in elite team sport athletes. J Strength Cond Res 2012;26:953-60.

5 Gabbett TJ, Domrow N. Relationships between training load, injury and fitness in sub-elite collision sport athletes. J Sport Sci 2007;25:1507-19.

6 Koutoures CG, Gregory AJ, American Academy of Pediatrics. Council on Sports Medicine and Fitness. Injuries in youth soccer. Pediatrics 2010;125:410-14.

7 Ekstrand J, Hägglund $M$, Waldén $M$. Injury incidence and injury patterns in professional football: the UEFA injury study. Br J Sports Med 2011;45:553-8.

8 Rogalski B, Dawson B, Heasman J, et al. Training and game loads and injury risk in elite Australian footballers. J Sci Med Sport 2013;16:499-503.

9 Colby MJ, Dawson B, Heasman J, et al. Accelerometer and GPS-derived running loads and injury risk in elite Australian footballers. J Strength Cond Res 2014;28:2244-52.

10 Hunter F, Bray J, Towlson C, et al. Individualisation of time-motion analysis: a method comparison and case report series. Int J Sports Med 2015;36:41-8.

11 Banister $E_{1}$ Calvert $T$, Savage $M$, et al. A systems model of training for athletic performance. Aust J Sport Med 1975;7:57-61.

12 Hulin BT, Gabbett TJ, Lawson DW, et al. The acute:chronic workload ratio predicts injury: high chronic workload may decrease injury risk in elite rugby league players. Br J Sports Med 2016:50:231-6.

13 Hulin BT, Gabbett TJ, Blanch P, et al. Spikes in acute workload are associated with increased injury risk in elite cricket fast bowlers. Br J Sports Med 2014:48:708-12.

14 Gabbett TJ. The training-injury prevention paradox: should athletes be training smarter and harder? Br J Sports Med 2016;50:273-80.

15 Ehrmann FE, Duncan CS, Sindhusake D, et al. GPS and injury prevention in professional soccer. J Strength Cond Res 2016;30:360-7.

16 Fuller CW, Ekstrand J, Junge $A$, et al. Consensus statement on injury definitions and data collection procedures in studies of football (soccer) injuries. $\mathrm{Br}$ J Sports Med 2006:40:193-201.

17 Wang Y, Chen HJ. Use of percentiles and z-scores in anthropometry. In: Preedy VR ed. Handbook of anthropometry: physical measures of human form in health and disease. New York, NY: Springer Science and Business Media, 2012:29-48.

18 Gabbett TJ, Jenkins DG, Abernethy B. Physical demands of professional rugby league training and competition using microtechnology. J Sci Med Sport 2012;15:80-6.

19 Wong P, Hong Y. Soccer injury in the lower extremities. Br J Sports Med 2005;39:473-82

20 Varley MC, Fairweather IH, Aughey RJ. Validity and reliability of GPS for measuring instantaneous velocity during acceleration, deceleration, and constant motion. J Sports Sci 2012:30:121-7.

21 Coutts AJ, Duffield R. Validity and reliability of GPS devices for measuring movement demands of team sports. J Sci Med Sport 2010;13:133-5.

22 Gabbe BJ, Bennell KL, Finch CF, et al. Predictors of hamstring injury at the elite level of Australian football. Scand J Med Sci Sports 2006;16:7-13.

23 Bahr R, Home I. Risk factors for sports injuries - a methodological approach. $\mathrm{Br} \mathrm{J}$ Sports Med 2003:37:384-92. 